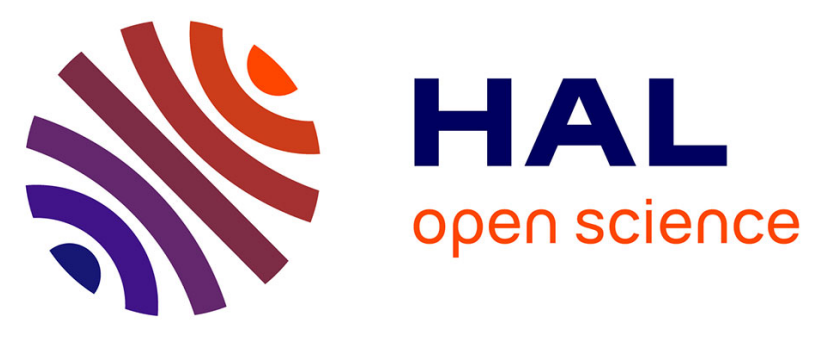

\title{
Esterification of Vitamin A by the Human Placenta Involves Villous Mesenchymal Fibroblasts
}

Vincent Sapin, Samira Chaïb, Loïc Blanchon, Marie Cécile

Alexandre-Gouabau, Didier Lémery, Françoise Charbonne, Denis Gallot, Bernard Jacquetin, Bernard Dastugue, Véronique Azaïs-Braesco

\section{To cite this version:}

Vincent Sapin, Samira Chaïb, Loïc Blanchon, Marie Cécile Alexandre-Gouabau, Didier Lémery, et al. Esterification of Vitamin A by the Human Placenta Involves Villous Mesenchymal Fibroblasts. Pediatric Research, 2000, 48 (4), pp.565 - 572. 10.1203/00006450-200010000-00024 . hal-01918619

\author{
HAL Id: hal-01918619 \\ https://hal.uca.fr/hal-01918619
}

Submitted on 19 Dec 2018

HAL is a multi-disciplinary open access archive for the deposit and dissemination of scientific research documents, whether they are published or not. The documents may come from teaching and research institutions in France or abroad, or from public or private research centers.
L'archive ouverte pluridisciplinaire HAL, est destinée au dépôt et à la diffusion de documents scientifiques de niveau recherche, publiés ou non, émanant des établissements d'enseignement et de recherche français ou étrangers, des laboratoires publics ou privés.

\section{(ㅇ)(1) $\$$}

Distributed under a Creative Commons Attribution - NonCommerciall 4.0 International 


\title{
Esterification of Vitamin A by the Human Placenta Involves Villous Mesenchymal Fibroblasts
}

\author{
VINCENT SAPIN, SAMIRA CHAÏB, LOÏC BLANCHON, MARIE-CÉCILE ALEXANDRE-GOUABAU, \\ DIDIER LÉMERY, FRANÇOISE CHARBONNE, DENIS GALLOT, BERNARD JACQUETIN, \\ BERNARD DASTUGUE, AND VÉRONIQUE AZAIS-BRAESCO \\ INSERM U.384, Laboratoire de Biochimie, Faculté de Médecine [V.S., L.B., B.D.], INRA UMMM, Equipe \\ Vitamines, Centre de Recherche en Nutrition Humaine [S.C., M.-C.A.-G., V.A.-B.], Unité de Médecine \\ Materno-Foetale, Maternité de l'Hôtel-Dieu [D.L., D.G., B.J.], and Laboratoire de Virologie Médicale, \\ Centre Hospitalo-Universitaire [F.C.], 63000 Clermont-Ferrand, France
}

\begin{abstract}
ABST
Vitamin A (retinol) and its active derivatives (retinoic acids)
are essential for growth and development of the mammalian
fetus. Maternally derived retinol must pass the placenta to reach
the developing fetus. Despite its apparent importance, little is
known concerning placental transfer and metabolism of retinol,
and particularly of placental production and storage of retinyl
esters. To elucidate this metabolic pathway, we incubated, in the
presence of retinol, 1 ) human full-term placental explants and 2)
primary cultures of major cells types contributing to placental
function: trophoblasts and villous mesenchymal fibroblasts. We
used HPLC to determine the types and concentrations of retinyl
esters produced by these explants and cells. About 14\% of total
cellular retinol in placental explants was esterified. The most
abundant esters were myristate and palmitate. Primary cell cul-
\end{abstract}
In addition to their essential roles in vision, growth, and maintenance of differentiated epithelia, vitamin A (retinol) and its active derivatives, the RAs, are required for normal mammalian reproduction and fetal development $(1,2)$. Maternal vitamin A deficiency can result in fetal death or in a spectrum of malformations, the fetal vitamin A deficiency syndrome (3-6). Excessive vitamin A intake can also produce a spectrum of congenital defects, in a dose- and developmental stagedependent manner $(7,8)$. Because there is no de novo fetal synthesis of retinol, the developing mammalian embryo is dependent on the maternal circulation for its vitamin A intake. The presence of measurable hepatic vitamin A stored at birth is indicative of the functionality and importance of placental

Received September 10, 1999; accepted May 22, 2000

Correspondence and reprint requests: Vincent Sapin, M.D., INSERM U. 384, Laboratoire de Biochimie Médicale, Faculté de Médecine et de Pharmacie, 28, Place Henri Dunant, BP 38, 63000 Clermont-Ferrand, France. tures showed that fibroblasts efficiently produced retinyl esters, but trophoblasts did not. In both types of experiments, no retinyl esters were detected in the culture medium, suggesting that retinyl esters were produced for storage purpose. These results suggest that villous mesenchymal fibroblasts are primary sites of retinol esterification and storage in the placenta. (Pediatr Res 48: 565-572, 2000)

$\quad$ Abbreviations
RA, retinoic acid
RBP, retinol binding protein
HBSS, Hanks' balanced salt solution
DMEM, Dulbecco's modified Eagle medium

transport during pregnancy $(9,10)$. Abnormalities of placental transfer could have serious consequences on fetal development and integrity.

Despite its apparent importance, little is known about placental transfer and metabolism of retinoids. This question has been approached in animal models (sheep, mouse, monkey), but the placental metabolism of retinoids is difficult to deduce from studies in the intact animal, and extrapolation of these results to humans is uncertain (11-13). Measurements of human placental, maternal, and cord retinoid concentrations have been reported, but they shed little light on the metabolic pathway $(14,15)$. Experiments using human perfused placenta and full-term human placental tissues in vitro have yielded controversial results concerning retinoid metabolism, especially the ability of the placenta to produce and store retinyl esters from retinol $(16,17)$.

To better characterize retinoid metabolism, we have investigated placental capacity to esterify retinol into retinyl esters of full-term placental explants. Primary cultures of the major types of cells contributing to the placenta (trophoblasts and 
mesenchymal fibroblasts) were tested to determine their individual capacity for esterification.

\section{METHODS}

Chemicals. All-trans retinol, trypsin, DNase, collagenase H, and human purified RBP were purchased from Sigma Chemical Co.-Aldrich (L'isle d'Abeau, Chesnes, France). HBSS, DMEM, RPMI 1640, glutamine, penicillin/streptomycin, and FCS were purchased from Life Technologies (Cergy, France). For all experiments, retinol was prepared as $1000 \times$ stock solution in ethanol. The maximal ethanol concentration to which the cells and tissues were exposed was $0.1 \%$. RetinolRBP complex was prepared and purified as previously described (18).

Placentas. Nine placentas from normal pregnancies were collected in the Department of Obstetrics and Gynecology at the Maternity of Hôtel-Dieu Hospital (Clermont-Ferrand, France). All the mothers gave their written informed consent before participation in accordance with the ethical principles expressed in the Declaration of Helsinki regarding human experimentation. The local Institutional Review Board has approved all the human studies. Term placentas of clinically normal pregnancies were obtained after delivery by cesarean section (placentas from vaginal deliveries were excluded to reduce risks of potential infections and tissue degradation). They were immediately collected and used within 15 to 30 min. Characteristics of the pregnant women and their babies are presented in Table 1. All the babies were healthy, and their morphometry scores were in the standard range for French babies (19). Growth, development, and postpartum changes were normal for all mothers and babies based on a medical examination that occurred in the $7 \mathrm{~d}$ after delivery.

Explant tissue incubation. Placental tissue (chorionic villus) was minced ( 1 to $2 \mathrm{~mm}^{3}$ ) and washed three times in sterile cold HBSS before incubation. Explants were immersed in Falcon flasks containing $50 \mathrm{~mL}$ of DMEM supplemented with $20 \mathrm{mM}$ glutamine, $10 \mathrm{U} / \mathrm{mL}$ penicillin, $100 \mu \mathrm{g} / \mathrm{mL}$ streptomycin, and $10 \%$ FCS (16). Retinol (free or bound to RBP) was added at a final concentration of $2 \mu \mathrm{M}$. When retinol was

Table 1. Characteristics of pregnant women and babies

\begin{tabular}{|c|c|c|c|}
\hline \multicolumn{2}{|c|}{ Women $(n=9)$} & \multicolumn{2}{|c|}{ Newborn $(n=9)$} \\
\hline Age $(y)$ & $30.1 \pm 3.5$ & Sex ratio (male/female) & $6 / 3$ \\
\hline $\begin{array}{l}\text { Term (d of } \\
\text { amenorrhea) }\end{array}$ & $267 \pm 6$ & Weight at birth (g) & $3198 \pm 217$ \\
\hline $\begin{array}{l}\text { Number of } \\
\text { pregnancy }\end{array}$ & & Weight of placenta $(\mathrm{g})$ & $545 \pm 77$ \\
\hline First & 3 & $\begin{array}{l}\text { Percentile of babies weight } \\
(\%)\end{array}$ & $51.3 \pm 17.2$ \\
\hline \multirow[t]{3}{*}{ Second and more } & 6 & Length $(\mathrm{cm})$ & $51.2 \pm 3.7$ \\
\hline & & Anthropometry & \\
\hline & & $\begin{array}{l}\text { Head circumference }(\mathrm{cm}) \\
\text { Thoracic circumference } \\
(\mathrm{cm})\end{array}$ & $\begin{array}{l}34.7 \pm 1.7 \\
33.2 \pm 1.5\end{array}$ \\
\hline
\end{tabular}

Age of mothers, term of gestation, anthropometric data of the babies (weight at birth, percentile of weight, length, head circumference, thoracic circumference), and weight of placenta are indicated by means \pm SD. All the data were collected during the last required antenatal medical examination for mothers (8th month) and immediately after birth for the babies. added free and diluted in ethanol, the maximal ethanol concentration to which the explants were exposed was $<0.1 \%$. As a negative control, explants were incubated only with vehicle (ethanol). Incubations were performed at $37^{\circ} \mathrm{C}$ in a humidified incubator with $5 \% \mathrm{CO}_{2} / 95 \%$ air at $37^{\circ} \mathrm{C}$. Incubations were terminated by washing the placental explants twice with cold PBS. All tissue samples were blotted dry and stored under nitrogen at $-70^{\circ} \mathrm{C}$ until further processing.

Primary placental fibroblast purification and incubation. Villous fibroblasts from placental mesenchyme were obtained using the modified method of Schwab et al. (20). Briefly, chorionic villi were washed with sterile cold HBSS. The tissue was coarsely minced and digested in $2 \mathrm{~mL}$ of $0.25 \%$ trypsin in HBSS without calcium and magnesium for $45 \mathrm{~min}$ at $37^{\circ} \mathrm{C}$. The first digest product was transferred and incubated for $1 \mathrm{~h}$ at $37^{\circ} \mathrm{C}$ in a second medium $(0.1 \%$ trypsin and $0.1 \%$ collagenase $\mathrm{H}$ in HBSS without calcium and magnesium). This digest was centrifuged at $4000 \mathrm{rpm}$, and the supernatant was discarded. The pellet was resuspended in $6 \mathrm{~mL}$ of RPMI 1640 containing $20 \mathrm{mM}$ glutamine, $10 \mathrm{U} / \mathrm{mL}$ penicillin, $100 \mu \mathrm{g} / \mathrm{mL}$ streptomycin, and 10\% FCS. Purity of isolated fibroblasts was examined by morphologic and immunologic (cytoplasmic vimentin-positive immunoreactivity) characteristics $(21,22)$. Fibroblasts at 50 to $60 \%$ confluence were incubated with $2 \mu \mathrm{M}$ retinol (free or bound to $\mathrm{RBP}$ ). When retinol was added free and diluted in ethanol, the maximal ethanol concentration to which the fibroblasts were exposed was $<0.1 \%$. As a negative control, fibroblasts were incubated with vehicle (ethanol). Primary purified cutaneous (skin) and MRC5 (pulmonary embryonic fibroblast cell line) fibroblasts were also cultured and incubated in RPMI 1640 as above. All the cultures and incubations were performed in a humidified incubator with $5 \%$ $\mathrm{CO}_{2} / 95 \%$ air at $37^{\circ} \mathrm{C}$.

Purification, differentiation, and incubation of primary cytotrophoblasts. Cytotrophoblasts were obtained by using the modified method of Kliman et al. (23). Villous tissue was dissected free of membranes and vessels. They were minced in cold sterile HBSS and subjected to repeated trypsin-DNase digestions as described (23). The resulting cell suspension was carefully layered over a discontinuous Percoll gradient (5 to $70 \%$ ) and centrifuged (20 min, $1500 \mathrm{rpm}$ ). The homogeneous population of mononuclear cells, contained in the middle layer (density $1.048-1.062 \mathrm{~g} / \mathrm{L}$ ) consisted of $>95 \%$ cytotrophoblast cells. For primary culture, the cells were plated in 90-mm Petri culture dishes $\left(5 \times 10^{6}\right.$ cells per dish) with DMEM supplemented with $20 \mathrm{mM}$ glutamine, $10 \mathrm{U} / \mathrm{mL}$ penicillin, 100 $\mu \mathrm{g} / \mathrm{mL}$ streptomycin, and 10\% FCS. Cultures and retinol incubations were always performed in humidified $5 \% \mathrm{CO}_{2} / 95 \%$ air incubator at $37^{\circ} \mathrm{C}$ (as described for fibroblasts). Purity of primary cytotrophoblasts was verified by morphologic and immunologic characteristics [cytokeratin- and human placental lactogen-positive immunoreactivity (23-25)]. Differentiation of cytotrophoblasts into syncytiotrophoblasts was monitored by measuring chorionic gonadotrophic hormone in the culture medium by immunochemiluminescent assay (ACS 180, Ciba Corning). Retinol and ethanol incubations were performed as described above. 
Chromatographic analysis. Tissues and cells were harvested in cold PBS. The cells were collected by scraping, resuspended in PBS, and sonicated on ice. All-trans retinol and retinyl esters were assayed from $1 \mathrm{~g}$ of placental tissue, $5 \times 10^{6}$ cells, or $0.5 \mathrm{~mL}$ of culture medium, as previously described with some minor modifications $(26,27)$. An equal volume of ethanol containing an internal standard (retinyl laurate for vitamin A) was added to each sample. They were then extracted twice with 2 volumes of hexane. After evaporation to dryness, the extract was dissolved in $250 \mu \mathrm{L}$ of a mixture of dichloromethane-methanol $(35: 65 ; \mathrm{vol} / \mathrm{vol})$. The compounds were analyzed by reverse-phase HPLC on a Waters apparatus equipped with a 600 pump, a 710 automatic injector, a 996 diode array detector and controlled by Millenium software 2.1. For retinol and retinyl ester determinations, the samples were eluted on a C18 column (Nucleosil, $250 \times 4.6 \mathrm{~mm}$ ) with pure methanol as the mobile phase $(2 \mathrm{~mL} / \mathrm{min})$; the detection was performed at $325 \mathrm{~nm}$ and $292 \mathrm{~nm}$. Identification was based on co-elution with authentic standards and UV spectrum comparisons. Quantification involved internal standardization and dose-response curves established with authentic standards.

DNA and protein concentration determinations. In all the studies, retinoid concentration assays were normalized to DNA or protein concentrations. DNA concentration was measured by a spectrofluorometric method described previously by Labarca and Paigen (28). Protein concentrations of the cellular homogenates were determined using the Biuret method on the Hitachi 911 from Boehringer Mannheim Diagnostics (29). Similar results were obtained when retinoid concentrations were normalized to DNA content or protein concentration; we chose to express our results normalized to DNA content for all the cell culture experiments.

Statistical analysis. All experiments were repeated on nine placental explants or primary cell cultures. Mean values and SD were calculated for all retinoid variables. Statistical comparisons were performed using ANOVA and Fisher's exact test. Statistical procedures were performed with the StatView program (Abacus Concepts, Inc., Berkeley, CA, U.S.A.). For all the studies, statistical significance was considered at $p<$ 0.05 .

\section{RESULTS}

Retinyl ester production in placental explants. As vitamin A is usually esterified within tissues, the production of vitamin
A esters in full-term placental explants was investigated. To explore retinyl ester production, retinol was added directly to the medium or bound to its blood carrier protein, RBP. During all the tissue or cell incubations, we checked the stability of the in vitro-generated RBP-retinol complex and the absence of nonspecific release of retinol from this complex (data not shown). Table 2 shows the concentrations of retinol and retinyl fatty acyl esters in placental extracts obtained 6 and $24 \mathrm{~h}$ after incubation with retinol (free or bound to RBP). We found that maximal esterification of free retinol was already achieved after $6 \mathrm{~h}$ of incubation (14.3\% of the total cellular retinol esterified). In contrast, a quantitative increase of cellular retinyl esters was observed between $6(10.2 \%)$ and $24 \mathrm{~h}(14.9 \%)$ of incubation with retinol bound to RBP. However, at the end of incubation $(24 \mathrm{~h})$, no statistical difference could be observed between the percentage of retinyl esters produced by retinol free of and bound to RBP. The values obtained in these experiments are comparable to those obtained in previous studies (30).

HPLC was able to distinguish between retinyl myristate, palmitate, and stearate concentrations $(26,27)$. Only retinyl myristate was present at significant levels before retinol incubation (Table 2). After retinol incubation bound or unbound to RBP, the most abundant esters, in decreasing order of abundance, were myristate, palmitate, and stearate. Retinyl esters were not detected in the culture medium, suggesting an absence of release of retinyl esters formed in situ. To elucidate which cells are involved in placental esterification of retinol, we studied this biochemical reaction in primary cultures of the different cell types constitutive of the human placenta.

Esterification of retinol by primary placental fibroblasts in culture. Figure 1 shows the intracellular concentrations of retinol and retinyl fatty acyl esters in primary fibroblast cultures collected from 3 to $24 \mathrm{~h}$ after incubation with retinol (free or bound to RBP), or with ethanol as a control. As presented in Figure $1 A$, free retinol added to the culture medium is rapidly taken up by fibroblasts, and little change in cellular retinol content is observed after $3 \mathrm{~h}$. The uptake of retinol bound to RBP occurs more slowly (but linearly) than when retinol was added directly to the culture medium of mesenchymal fibroblasts. The time course of retinol esterification is presented in Figure $1 B$. As previously described for human skin fibroblasts $(31,32)$, primary human placental fibroblasts are able to

Table 2. Esterification of retinol by tissue explants from human placenta at term

\begin{tabular}{|c|c|c|c|c|}
\hline \multirow[b]{2}{*}{ Explant culture times } & \multicolumn{4}{|c|}{ Retinoid concentrations ( $\mu \mathrm{mol} / \mathrm{g}$ of placental explants) } \\
\hline & Retinol & $\begin{array}{l}\text { Retinyl } \\
\text { Myristate }\end{array}$ & $\begin{array}{l}\text { Retinyl } \\
\text { palmitate }\end{array}$ & $\begin{array}{l}\text { Retinyl } \\
\text { stearate }\end{array}$ \\
\hline $6 \mathrm{~h}$ free retinol incubation & $4988 \pm 750^{\mathrm{b}}$ & $520 \pm 105^{\mathrm{f}}$ & $251 \pm 67^{j}$ & $64 \pm 15^{\mathrm{m}}$ \\
\hline 6 h RBP-retinol incubation & $2397 \pm 510^{\mathrm{c}}$ & $160 \pm 55^{\mathrm{g}}$ & $103 \pm 38^{\mathrm{k}}$ & $21 \pm 3^{n}$ \\
\hline $6 \mathrm{~h}$ ethanol incubation & $159 \pm 37^{\mathrm{a}}$ & $16 \pm 4^{\mathrm{e}}$ & $1 \pm 0.5^{\mathrm{i}}$ & $10 \pm 2^{1}$ \\
\hline $24 \mathrm{~h}$ free retinol incubation & $4995 \pm 720^{b}$ & $511 \pm 98^{\mathrm{f}}$ & $243 \pm 61^{\mathrm{j}}$ & $78 \pm 19^{\mathrm{m}}$ \\
\hline
\end{tabular}

Placentas were obtained after cesarean delivery. Retinol (free or bound to RBP) was added to a final $2 \mu \mathrm{M}$ concentration; ethanol was used as a negative control. Incubations were blocked after 6 or 24 h. Experiments were repeated on nine different placental explants. For each retinoid, means of the nine results are presented with their SD. For each specific retinoid, different superscripts denote significant difference (tested by Fisher's exact test; $p<0.05$ ). 


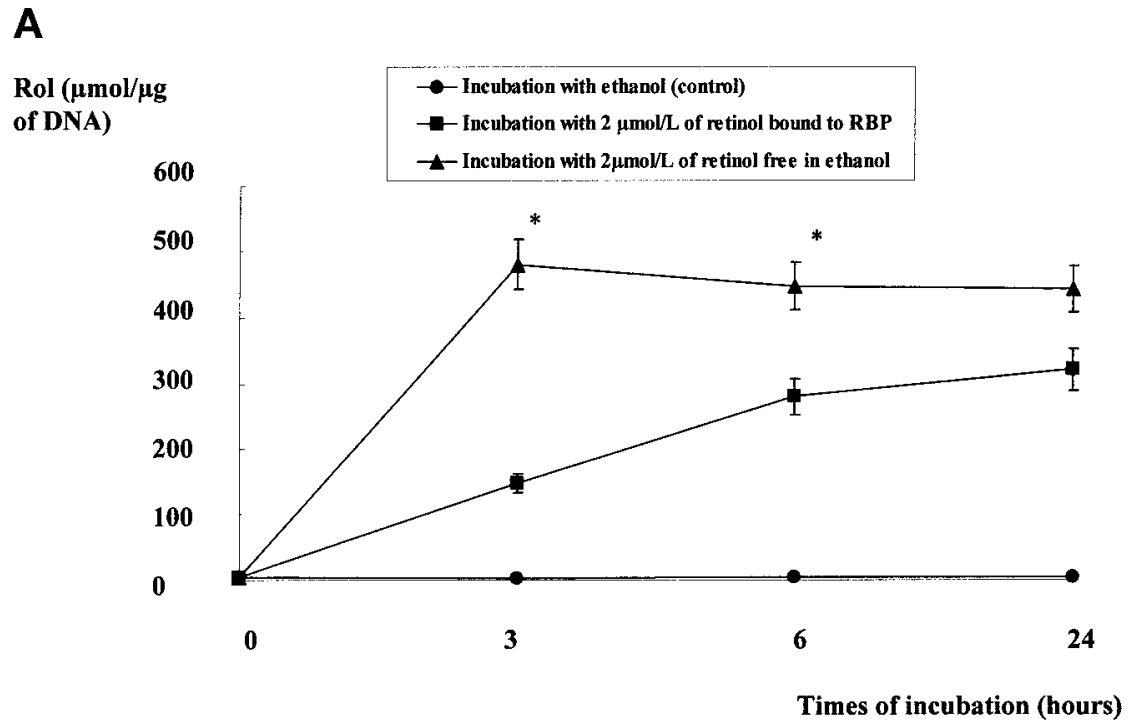

B

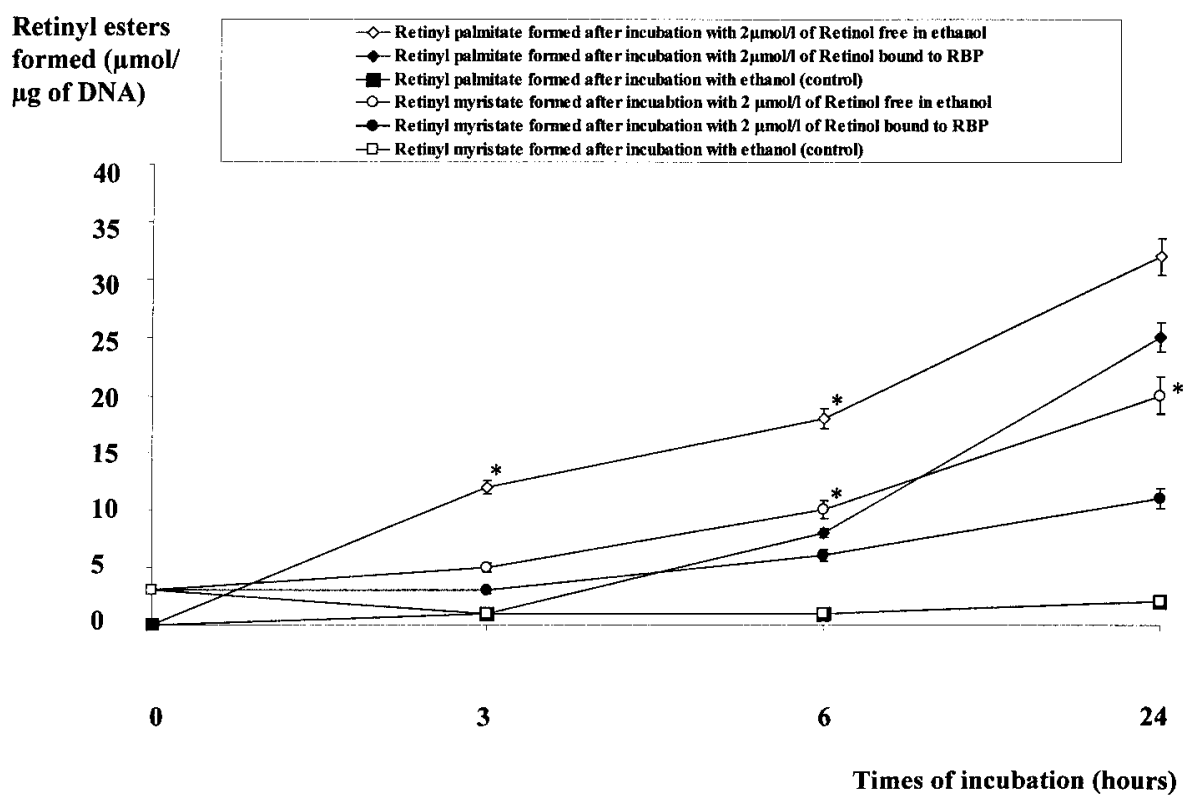

Figure 1. Intracellular concentrations of retinol $(\mathrm{Rol} ; A)$ and retinyl esters $(B)$ in placental fibroblasts after retinol incubation. Primary placental fibroblasts were treated with $2 \mu \mathrm{mol} / \mathrm{L}$ retinol (added directly to the culture medium or bound to RBP) during different times of incubation ( 3 to $24 \mathrm{~h})$. The intracellular retinol concentrations $(A)$ and retinyl ester concentrations $(B)$ correspond to the means and SD values obtained from nine different culture experiments. Error bars represent the SD of the nine experiments. Where error bars are not visible, they were smaller than the diameter of the symbol. For each incubation time, an asterisk denotes statistical differences between intracellular retinol, retinyl palmitate, or retinyl myristate values obtained from free retinol and retinol bound to RBP incubation (tested by Fisher's exact test; $p<0.05$ ).

esterify retinol. Conversion of free retinol into retinyl esters is rapid: at the earliest sampling time $(3 \mathrm{~h})$, significant production of retinyl palmitate was observed. The accumulated amount of retinyl esters increased steadily to reach a maximum of about $10.8 \%$ of total cellular retinol at $24 \mathrm{~h}$ of incubation time with free retinol. Retinyl palmitate was always the major ester produced for all times of incubation with free retinol (Fig. 1B). No significant ester production was detected with ethanol incubation (Fig. 1B). Retinol delivered via RBP was also converted to retinyl esters; but more slowly than after incubation with free retinol: no significant increase of retinyl esters $(2.1 \%)$ was detected at $3 \mathrm{~h}$ in contrast to $3 \mathrm{~h}$ of free retinol incubation $(3.7 \%)$. At the end of incubation $(24 \mathrm{~h})$, the per- centage of retinol converted into retinyl esters $(10,8 \%)$ was the same whether the retinol was added directly to the medium or bound to RBP. In conclusion, although amounts of retinol taken up and converted into retinyl esters by fibroblasts are different depending on whether it is delivered free or bound to RBP, we could not find any differences in the relative percentage and profile of retinyl esters formed. Experiments using primary cutaneous and MRC5 (pulmonary embryonic fibroblast cell line) fibroblasts gave similar results for the rate of free retinol esterification (Table 3). This suggests that the ability of placental fibroblasts to esterify retinol is not tissuespecific but rather reflects an intrinsic and ubiquitous property of human fibroblasts. 
Table 3. Cellular content of retinol and retinyl esters in three different types of human fibroblasts, after 24 h of free retinol incubation

\begin{tabular}{|c|c|c|c|c|}
\hline \multirow[b]{2}{*}{ Cell type } & \multicolumn{4}{|c|}{ Retinoid concentrations ( $\mu \mathrm{mol} / \mu \mathrm{g}$ of DNA) } \\
\hline & Retinol & $\begin{array}{c}\text { Retinyl } \\
\text { myristate }\end{array}$ & $\begin{array}{c}\text { Retinyl } \\
\text { palmitate }\end{array}$ & $\begin{array}{l}\text { Retinyl } \\
\text { stearate }\end{array}$ \\
\hline $0 \mathrm{~h}$ free retinol incubation & $4 \pm 2^{\mathrm{a}}$ & $3 \pm 2^{\mathrm{g}}$ & $0^{\mathrm{m}}$ & $0^{\mathrm{s}}$ \\
\hline $24 \mathrm{~h}$ free retinol incubation & $442 \pm 37^{\mathrm{b}}$ & $20 \pm 5^{\mathrm{h}}$ & $32 \pm 7^{\mathrm{n}}$ & $2 \pm 1^{\mathrm{t}}$ \\
\hline \multicolumn{5}{|l|}{ Cutaneous fibroblasts } \\
\hline \multicolumn{5}{|c|}{ MRC5 (embryonic pulmonary) fibroblasts } \\
\hline $0 \mathrm{~h}$ free retinol incubation & $2 \pm 1^{\mathrm{e}}$ & $1 \pm 1^{\mathrm{k}}$ & $0^{\mathrm{q}}$ & $0^{\mathrm{v}}$ \\
\hline $24 \mathrm{~h}$ free retinol incubation & $258 \pm 19^{f}$ & $8 \pm 3^{1}$ & $16 \pm 5^{\mathrm{r}}$ & $3 \pm 1^{\mathrm{w}}$ \\
\hline
\end{tabular}

Primary cultures of placental and cutaneous fibroblasts and of an embryonic pulmonary fibroblast cell line (MRC5) were incubated with $2 \mu \mathrm{M}$ retinol added directly to the culture for $24 \mathrm{~h}$. The intracellular retinol and retinyl ester concentrations correspond to the means and SD values obtained from five different culture experiments. For each specific retinoid, different superscripts denote significant differences (tested by Fisher's exact test; $p<0.05$ ).

Absence of esterification by primary cytotrophoblasts and syncytiotrophoblasts in culture. It is well established that cytotrophoblasts and syncytiotrophoblasts are the cells involved in the transfer of a large number of nutrients from the mother to the fetus and their metabolism. Therefore, we studied the ability of these cells to esterify retinol free and bound to RBP. In all the experiments, the initial cellular material was found to contain retinyl myristate. As presented in Figure $2 A$, the uptake of retinol bound to RBP occurs more slowly than when retinol was added directly to the culture medium of trophoblastic cells. Note that decrease of intracellular retinol levels between 6 and $24 \mathrm{~h}$ was found in both types of retinol incubation. Figure $2 B$ shows that retinol incubation did not lead to a significant retinyl myristate production, but was associated with a weak (but significant) esterification of retinol into retinyl palmitate by trophoblasts. Stearate was never detected at any step of the incubation. We could not find any differences in the relative percentage and profile of retinyl esters formed between incubation with retinol free or bound to RBP (Fig. 2B). Cytotrophoblasts are known to differentiate into syncytiotrophoblasts during normal culture (19). We performed 24-h retinol incubation after various times of trophoblastic cell culture $(24,48$, and 72 h), which correspond respectively to the cytotrophoblast, intermediary, and syncytiotrophoblast stages. Similar retinoid profiles were obtained at all these steps (data not shown).

The total retinyl esters found after $24 \mathrm{~h}$ of retinol incubation in placental fibroblasts and trophoblastic cells is 51.8 and 8.7 $\mu \mathrm{mol} / \mu \mathrm{g}$ of DNA, respectively. A 14.6-fold and 1.4-fold (not significant) increase in total retinyl esters during $24 \mathrm{~h}$ of retinol incubation was found in fibroblasts and trophoblasts, respectively, implying that the placental cells responsible for retinol esterification are fibroblasts.

\section{DISCUSSION}

Vitamin A and its active derivatives, the retinoids, are fundamental for development of the mammalian fetus $(2,6$, 10). The placenta plays a crucial role in regulation of transport and metabolism of maternal nutrients transferred to the fetus. Abnormalities in these placental functions can have deleterious consequences on fetal development $(8,33)$. Little is known about human placental retinol transfer and metabolism. Creech-Kraft et al. (34) demonstrated that even $96 \mathrm{~h}$ after administration of 13-cis RA, all-trans RA and 4-oxo metabolites are still found in the early human placenta. More recently, co-oxidation of all-trans retinyl acetate by lipoxygenase has been demonstrated in the human placenta (35). All these results indicate that the human placenta has the ability to isomerize and oxidize retinoids.

Our study demonstrates that human placental tissues at term and, more precisely, the villous mesenchymal fibroblasts, are able to esterify retinol. Human primary cutaneous fibroblasts are known to have this ability and to express the intracellular proteins (cellular RBP-1) and the necessary metabolic enzymes $(32,36)$ that allow this function. A recent study demonstrated the presence of cellular RBP-1 in villous mesenchymal cells of the human placenta (37). Added to our results, this implies that maternal retinol could be trapped by the mesenchymal fibroblasts and esterified in situ. Note that our preliminary results suggest the presence of one or both retinol esterifying enzymes, the lecithin retinol acyl transferase in these placental cells.

However, cytotrophoblasts or syncytiotrophoblasts express the putative placental RBP receptor (37) and are unable to esterify retinol in a significant manner. This study suggests that these trophoblastic cells are more involved in the transfer of retinol between mother and fetus, rather than in its metabolism. The retinyl esters that we detected after cytotrophoblast purification are probably related to the capture of maternal chylomicrons charged with newly digested retinyl esters (38). It has been established that trophoblastic cells express the receptors for LDL and VLDL lipoproteins $(39,40)$ and are able to take up and use lipoproteins (41). Furthermore, considering the life span $(96 \mathrm{~h})$ and the perpetual regeneration of the trophoblasts, stocks of retinyl esters have to be located in villous mesenchymal cells (fibroblasts) to be protected from a rapid and nonspecific hydrolysis and liberation.

We report here that the rate of esterification of retinol by mesenchymal fibroblasts and the types of retinyl esters synthesized are the same whether retinol is delivered free or bound to RBP. This agrees with other previous results observed for rat liver parenchymal cells (42) or human foreskin keratinocytes (43), suggesting an absence of cell surface RBP receptors on 
A

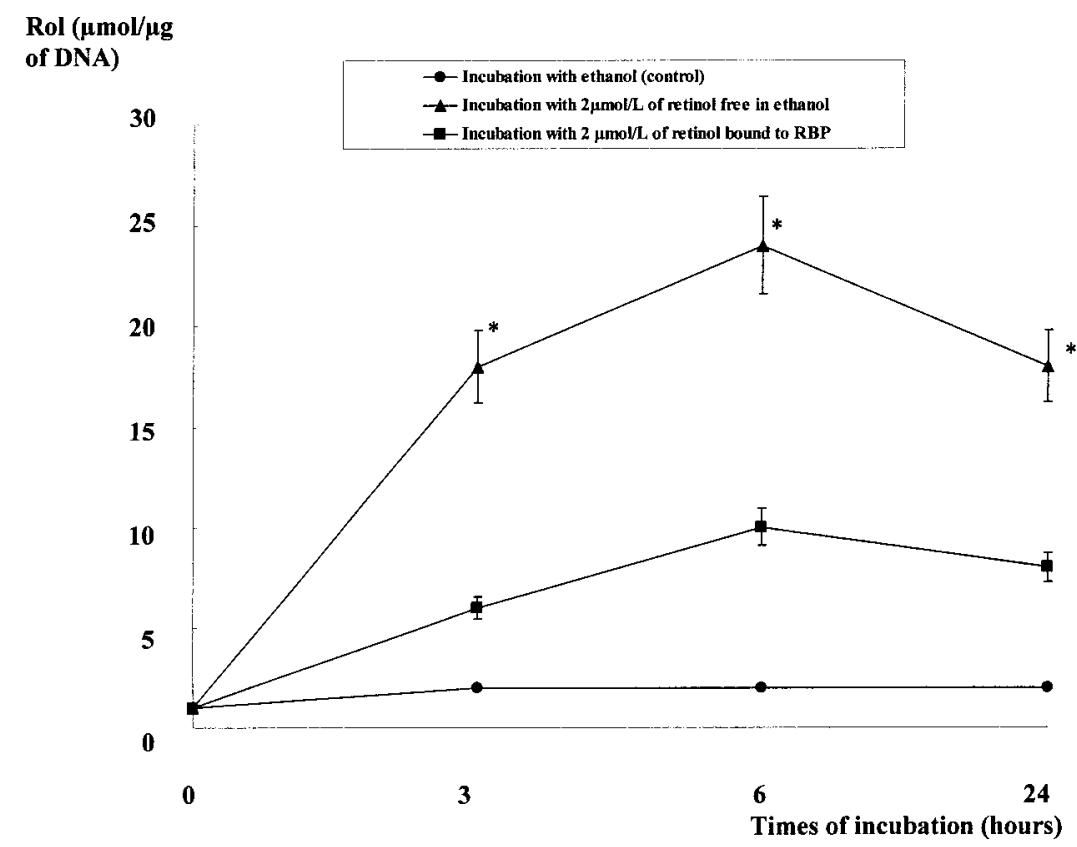

B

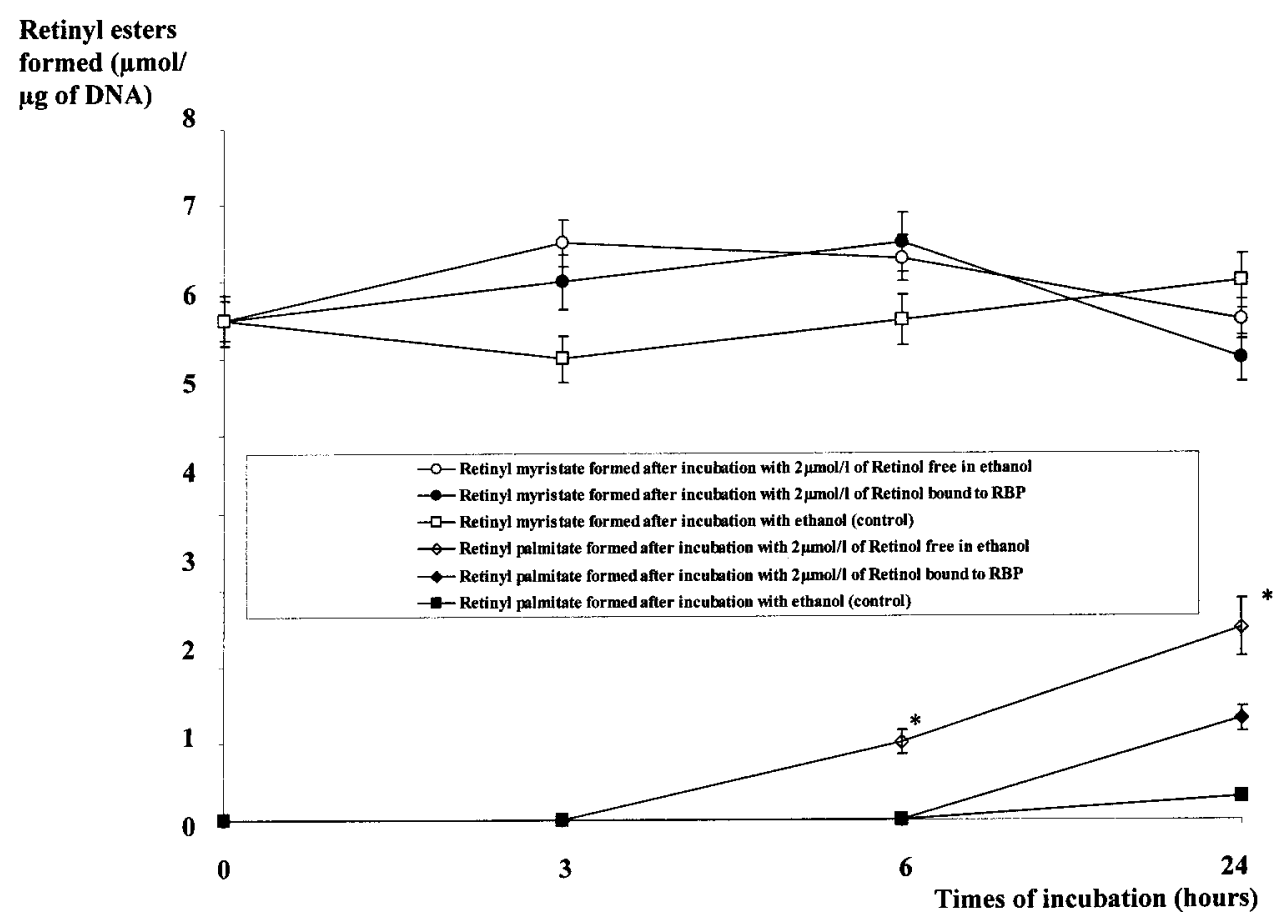

Figure 2. Intracellular concentrations of retinol $(\mathrm{Rol} ; A)$ and retinyl esters $(B)$ in trophoblastic cells after retinol incubation. Primary trophoblastic cells were treated with a final $2 \mu \mathrm{mol} / \mathrm{L}$ retinol (diluted in ethanol or bound to RBP), during different times of incubation ( 3 to $24 \mathrm{~h}$ ). Means of intracellular retinol concentrations $(A)$ and retinyl ester concentrations $(B)$ obtained from nine different culture experiments were presented with their SD. Error bars represent the $\mathrm{SD}$ of the nine experiments. Where error bars are not visible, they were smaller than the diameter of the symbol. For each incubation time, an asterisk denotes statistical differences between intracellular retinol, retinyl palmitate, or retinyl myristate values obtained from free retinol and retinol bound to RBP incubation (tested by Fisher's exact test; $p<0.05$ ).

mesenchymal fibroblasts. Recently, an immunohistologic study showed that staining for the RBP receptor protein was only observed in the apical part of the villous syncytiotrophoblast and in the placental macrophages (Hofbauer cells) (37). Because of the closed cellular contact between trophoblasts and fibroblasts in term placental villi, we propose that maternal retinol complexed with RBP could be captured by trophoblasts, then freely transferred to fibroblasts.

A discrepancy is observed between the esterification profiles obtained on tissue and cell culture experiments. In explants, 
retinyl myristate is the major ester formed, whereas in fibroblast cultures, an equilibrium between retinyl myristate and palmitate occurs. It has already been well demonstrated that vitamin A metabolism (especially retinyl ester production, storage, and hydrolysis) may be affected by the characteristics of the surrounding extracellular matrix, by soluble cytokine mediators (44), and by growth factors (epidermal growth factor) specific to placental tissue. In the primary isolated cell cultures, absence of such a complex placental environment could contribute to the differences observed in the profile and rate of retinyl ester production.

What is the function of retinyl esters in placenta? The fact that these compounds were never detected in our experimental conditions (i.e. without stimulus) in the culture medium suggests that retinyl esters are produced for storage. In agreement with this observation, retinyl esters also were never detected in human umbilical blood at delivery (15). It is well accepted that the placenta could be considered as a transitory, primitive functional liver during the first stages of development. During this period, the placenta stores retinol, waiting for liver maturity and functionality marked by the capacity to secrete RBP. In our study, the capacity of the human placenta at term to esterify retinol could be residual activity otherwise strongly present during early embryonic and fetal development.

This hypothesis is supported by results concerning the switch in retinoid content of embryonic and placental compartments during the development of the mouse conceptus (9). During early organogenesis, the retinyl ester content of the placenta is nearly 8 -fold higher than the content of the embryo, whereas at the end of gestation, the retinyl ester content of embryo is nearly 4-fold greater than that of the placenta. The timing of this crossover correlates with the apparent onset of retinol storage by the embryonic liver.

According to its capacity to rapidly store retinyl esters, the placenta could be considered as an efficient buffer to control retinol delivery between mother and fetus by 1 ) releasing retinol to the fetus when maternal intake is deficient, and 2) protecting the embryo from a potential excess of maternal retinol. Even if maternal retinoid concentrations were abnormally fluctuant, the placenta could prevent strong variability in quantity and quality of retinoids delivered to the fetus. By this mechanism, the placenta could play a preventive role against retinoid teratogenicity. This role is probably limited to physiologic retinol variations, and overwhelmed by medical or dietary maternal ingestion of retinoids responsible for fetal teratogenicity resulting from hypervitaminosis A. In addition, placental retinyl stores could be considered as a local reserve for placental use. Transformation of retinyl esters into active retinol derivatives (RAs) could be a simple way to regulate in situ cellular proliferation and differentiation. But to our knowledge, this retinoid metabolism has only been described in mouse and porcine placenta (45). During human pregnancy, maternal exposure to substances able to alter placental retinoid metabolism could provide a novel, additional explanation for fetal teratogenic pathology.

Acknowledgments. The authors thank Simon Ward, Dominey Yallop, and Pascal Dollé for critically reading the manuscript, and all the midwives for their availability, professional competence and kindness, which have made this study possible. We also thank the technicians of the Laboratory of Biochemistry and Immunology of Center Hospitalier Universitaire (Clermont-Ferrand) for their kind help.

\section{REFERENCES}

1. Wilson JG, Roth CB, Warkany J 1953 An analysis of the syndrome of malformations induced by maternal A deficiency: effects of restoration of vitamin A at various times in gestation. Am J Anat 92:189-217

2. Chambon P 1994 The retinoid signalling pathway: molecular and genetic analyses. Semin Cell Biol 5:115-125

3. Mason KE 1935 Foetal death, prolonged gestation and difficult parturition in the rat as result of vitamin A. Am J Anat 57:303-311

4. Wallingford JC, Underwood BA 1986 Vitamin A deficiency in pregnancy, lactation and the nursing child. In: Bauernfeind CJ (ed) Vitamin A Deficiency and Its Control. Academic Press, New York, pp 47-64

5. Takahashi YI, Smith JE, Winick M, Goodman DS 1975 Vitamin A deficiency and fetal growth and development in the rat. Am J Physiol 233:E263-E271

6. Morriss-Kay GM, Ward SJ 1999 Retinoids and embryonic development. Int Rev Cytol 188:73-133

7. Cohlan SQ 1953 Excessive intake of vitamin A as a cause of congenital anomalies in the rat. Science 117:535-536

8. Miller RK, Faber W, Asai M, D’Gregorio RP, Ng WW, Shah Y, Neth-Jessee L 1993 The role of the human placenta in embryonic nutrition: impact of environmental and social factors. Ann N Y Acad Sci 678:92-107

9. Satre MA, Ugen KE, Kochhar DM 1992 Developmental changes in endogenous retinoids during pregnancy and embryogenesis in the mouse. Biol Reprod 46:802810

10. Ross AC, Gardner EM 1994 The function of vitamin A in cellular growth and differentiation, and its roles during pregnancy and lactation. Adv Exp Med Biol 352:187-200

11. Ismadi SD, Olson JA 1982 Dynamics of the fetal distribution and transfer of vitamin A between rat fetuses and their mother. Int J Vitam Nutr Res 52:112-119

12. Donoghue S, Richardson DW, Sklan D, Kronfeld DS 2031982 Placental transport of retinol in sheep. J Nutr 112:2197-2203

13. Vahlquist A, Nilsson S 1984 Vitamin A transfer to the fetus and to the amniotic fluid in rhesus monkey (Macaca mulatta). Ann Nutr Metab 28:321-333

14. Dimenstein R, Trugo NM, Donangelo CM, Trugo LC, Anastacio AS 1996 Effect of subadequate maternal vitamin-A status on placental transfer of retinol and betacarotene to the human fetus. Biol Neonate 69:230-234

15. Sapin V, Alexandre MC, Cha239'95b S, Bournazeau JA, Sauvant P, Borel P, Jacquetin B, Grolier P, Lémery D, Dastugue B, Aza239'95s-Braesco V 1999 Vitamin A status at the end of term pregnancy in well-nourished French women: evidence of modified retinol-binding protein saturation with retinol. Am J Clin Nutr 71:537-543

16. Torma H, Vahlquist A 1986 Uptake of vitamin A and retinol-binding protein by human placenta in vitro. Placenta 7:295-305

17. Dancis J, Levitz M, Katz J, Wilson D, Blaner WS, Piantedosi R, Goodman DS 1992 Transfer and metabolism of retinol by the perfused human placenta. Pediatr Res 32:195-199

18. Siegenthaler G $1990 \mathrm{Gel}$ electrophoresis of cellular retinoic acid binding proteins, cellular retinol binding proteins and serum retinol binding protein. Methods Enzymol 189:299-307

19. Leroy B, Lefort F 1971 The weight and size of newborn infants at birth. Rev Fr Gynecol Obstet 66:391-396

20. Schwab ME, Muller C, Schmid-Tannwald I 1984 Fast and reliable culture method for cells from 8-10 week trophoblast tissue. Lancet 12:1082-1084

21. Nakamura Y, Ohta Y 1990 Immunohistochemical study of human placental stromal cells. Hum Pathol 21:936-940

22. Kohnen G, Kertschanska S, Demir R, Kaufmann P 1996 Placental villous stroma as a model system for myofibroblast differentiation. Histochem Cell Biol 105:415-429

23. Kliman HJ, Nestler JE, Sermasi E, Sanger JM, Strauss 3d JF 1986 Purification, characterization, and in vitro differentiation of cytotrophoblasts from human term placentae. Endocrinology 118:1567-1582

24. Daya D, Sabet L 1991 The use of cytokeratin as a sensitive and reliable marker for trophoblastic tissue. Am J Clin Pathol 95:137-141

25. Polliotti BM, Abramowsky C, Schwartz DA, Keesling SS, Lee GR, Caba J, Zhang W, Panigel M, Nahmias AJ 1995 Culture of first-trimester and full-term human chorionic villus explants: role of human chorionic gonadotropin and human placental lactogen as a viability index. Early Pregnancy 1:270-280

26. Borel P, Tyssandier V, Mekki N, Grolier P, Rochette Y, Alexandre-Gouabau MC, Lairon D, Azais-Braesco V 1998 Chylomicron beta-carotene and retinyl palmitate responses are dramatically diminished when men ingest beta-carotene with mediumchain rather than long-chain triglycerides. Nutrition 128:1361-1367

27. Borel P, Dubois C, Mekki N, Grolier P, Partier A, Alexandre-Gouabau MC, Lairon D, Azais-Braesco V 1997 Dietary triglycerides, up to $40 \mathrm{~g} / \mathrm{meal}$, do not affect preformed vitamin A bioavailability in humans. Eur J Clin Nutr 51:717-722

28. Labarca C, Paigen K 1980 A simple, rapid, and sensitive DNA assay procedure. Anal Biochem 102:344-352 
29. Camara PD, Wright C, Dextraze P, Griffiths WC 1991 Comparison of a commercial method for total protein with a candidate reference method. Ann Clin Lab Sci 21:335-339

30. Goodman DS, Blaner WS 1984 Biosynthesis, absorption and hepatic metabolism of retinol. In: Sporn MB, Roberts AB, Goodman DS (ed) The Retinoids, Vol 2. Academic Press, Orlando, FL, pp 2-39

31. Korner T, Rath FW, Schmidt H 1988 The ability of cultivated human skin fibroblast to store vitamin A: a contribution to the cytogenesis of the Ito cells of the liver. Exp Pathol 35:247-251

32. Takagawa K, Hirosawa K 1989 Uptake of retinol by cultured fibroblasts. Cell Struct Funct 14:353-362

33. Cross JC, Werb Z, Fisher SJ 1994 Implantation and the placenta: key pieces of the development puzzle. Science 266:1508-1518

34. Creech-Kraft J, Nau H, Lammer E, Olney A 1987 Embryonic retinoid concentration after maternal intake of isotretinoin. N Engl J Med 321:262-264

35. Datta K, Kulkarni AP 1996 Co-oxidation of all-trans retinol acetate by human term placental lipoxygenase and soybean lipoxygenase. Reprod Toxicol 10:105-112

36. Torma H, Lontz W, Liu W, Rollman O, Vahlquist A 1994 Expression of cytosolic retinoid-binding protein genes in human skin biopsies and cultured keratinocytes and fibroblasts. Br J Dermatol 131:243-249

37. Johansson S, Gustafson A, Donovan M, Eriksson U, Dencker L 1999 Retinoid binding proteins-expression patterns in the human placenta. Placenta 20:459-465

38. Blomhoff R 1994 Transport and metabolism of vitamin A. Nutr Rev 52:S13-S23
39. Grimes RW, Pepe GJ, Albrecht ED 1996 Regulation of human placental trophoblast low-density lipoprotein uptake in vitro by estrogen. J Clin Endocrinol Metab 81:2675-2679

40. Murata M, Kodama H, Goto K, Hirano H, Tanaka T 1996 Decreased very-lowdensity lipoprotein and low-density lipoprotein receptor messenger ribonucleic acid expression in placentas from preeclamptic pregnancies. Am J Obstet Gynecol $175: 1551-1556$

41. Winkel CA, Gilmore J, MacDonald PC, Simpson ER 1980 Uptake and degradation of lipoproteins by human trophoblastic cells in primary culture. Endocrinology 107:1892-1898

42. Van Bennekum AM, Blaner WS, Seifert-Bock I, Moukides M, Brouwer A, Hendriks HF 1993 Retinol uptake from retinol-binding protein (RBP) by liver parenchymal cells in vitro does not specifically depend on its binding to RBP. Biochemistry 32:1727-1733

43. Hodam JR, Creek KE 1998 Comparison of the metabolism of retinol delivered to human keratinocytes either bound to serum retinol-binding protein or added directly to the culture medium. Exp Cell Res 10:257-264

44. Davis BH, Vucic A 1989 Modulation of vitamin A metabolism during hepatic and intestinal cell culture. Biochim Biophys Acta 6:318-324

45. Parrow V, Horton C, Maden M, Laurie S, Notarianni E 1998 Retinoids are endogenous to the porcine blastocyst and secreted by trophectoderm cells at functionallyactive levels. Int J Dev Biol 42:629-632 